Can I get a job if I wear Hijab? An exploratory study of the perceptions of South Asian Muslim Women in the US and the UAE

Pasha-Zaidi, Nausheen

The Chicago School of Professional Psychology, USA (ninapzaidi@yahoo.com)

Masson, Tiffany

The Chicago School of Professional Psychology,USA (tmasson@thechicagoschool.edu)

Pennington, M. Nan

The Chicago School of Professional Psychology,USA (nepenny@gmail.com)

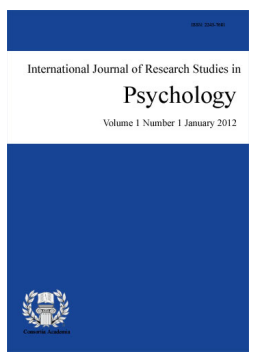

ISSN: 2243-7681 Online ISSN: 2243-769X

OPEN ACCESS

\title{
Abstract
}

The impact of the Islamic headscarf (hijab) on employment opportunities in Western contexts has been explored in a number of studies, but there is limited information on the topic as it applies to Islamic mainstream contexts. The current study explores the impact of the hijab on perceptions of employability among South Asian Muslim women in the United States (US) and the United Arab Emirates (UAE). Perceptions of women that wear hijab (hijabis) and women that do not wear hijab (non-hijabis) were analyzed. Both hijabis and non-hijabis perceived that wearing hijab in the US lowered the chances of applicants receiving a job offer. In the UAE, however, the results were mixed with non-hijabis perceiving that hijab has a negative effect on employability and hijabis perceiving the opposite effect. Implications of the results are discussed.

Keywords: Hijab; Islamic headscarf; employability; Muslim women 


\section{Can I get a job if I wear Hijab? An exploratory study of the perceptions of South Asian Muslim Women in the US and the UAE}

\section{Introduction}

Signs of anti-Islamic prejudice can be found in many Western countries and are often encapsulated in the use of the hijab, or Islamic headscarf, which is the most visible expression of the Islamic faith (Heibling, 2008; Rana, 2007; Dunn, Klocker, \& Salabay, 2007; Sheth, 2006; Fair, 2003). Complaints of religious discrimination are often centered on the use of Islamic attire (or ethnic attire that is presumed to be Islamic) in Western public spaces where public and private identities become key players in the debate between secularism and religious practice (Gole, 2003; Ruby, 2006; Droogsma, 2007). As a marker of Islam, the hijab has provided an arena for debate about women's rights and the appropriateness of religious symbols in public spaces. Bans on the wearing of the hijab in France and Turkey have made international headlines, exacerbating the division between those that are pro-hijab and those that are anti-hijab (Ajrouch, 2007). There is no argument among Muslim women that the headscarf is a necessary component of Islamic prayer; however, the incorporation of the hijab in public life continues to be an area of contention. Within the Muslim community, the hijab has often been used as a litmus test to determine the piety of Muslim women. Not surprisingly, women who wear the hijab are able to gain a higher level of social prestige within their Muslim communities, while the public display of their faith has made them more susceptible to discrimination in Western society (Vyas, 2008; Ali, 2005; Moore, 2007).

The practice of the hijab in the Islamic societies of the Middle East, on the other hand, is highly dependent on the country. The Gulf Cooperative Council (GCC) is a conglomerate of Middle Eastern nations that is headquartered in Riyadh and has six member states (Saudi Arabia, Oman, Bahrain, Kuwait, Qatar and the United Arab Emirates). Even though these countries share common histories and political systems (Kapiszewski, 2004), social norms regarding hijab vary. Whereas Saudi Arabian law requires the use of the hijab for all women, the United Arab Emirates (UAE) prides itself on being a tolerant and open-minded society that does not force women to abide by strict interpretations of Islamic mandates for dress. However, the fear of Western influences on local culture in the UAE has increased the pressure among many Muslim women to appear more religious through the use of the hijab. In many nations of the GCC, "because women are seen as the keepers of morality, they have been expected to make more of a show of their loyalty to Islam" (Al-Jenaibi, 2010, p. 66).

\section{Literature Review}

Employability among Muslims in Western contexts has been explored in a number of studies (Ghumman \& Jackson: 2010; Read, 2002; Persad \& Lukas, 2002; Lewis, 2007; Parker-Jenkins, Hartas, Irving, \&Barker, 1999; King \& Ahmad, 2010; Foroutan, 2008; Unkelbach, Schneider, Gode, \& Senft, 2010). For example, Ghumman and Jackson (2010) found that Muslim women in the US who wear hijab (hijabis) have lower expectations of receiving job offers than Muslim women who do not wear hijab (non-hijabis), especially with jobs requiring high levels of public contact.

Accordingly, Persad and Lukas' (2002) research demonstrated hijabis experience barriers to employment in manufacturing, sales and service sectors in Canada). Selection bias exists in Germany against women wearing hijab (Unkelback et. al, 2010, whereas, female job applicants in the US wearing Muslim attire were considered most employable for lower-status positions and least employable for high-status positions (Ghuman \& Jackson, 2008). Interestingly, there is no difference between interview offers for hijabis and non-hijabis, however, the interactions between applicants and employers in the American retail industry were shorter and more interpersonally negative for hijabis who did not provide evidence against stereotypical information (Ahmad, 2010). This current study adds to the existing literature by examining the effect of the hijab on South Asian Muslim women's perceptions of employability by comparing the perceptions of South Asian Muslim women in 
the United States (US) and the United Arab Emirates (UAE).

As hijab is a visible marker of a stigmatized group in Western societies, especially in the post-9/11 era, stereotype threat may affect the perceptions of employability among Muslims as well as their actual job performance. According to Stereotype Threat Theory people whose social groups have negative stereotypes associated with them will underperform in a way that is consistent with the stereotype (Steele and Aronson, 1995). As such, South Asian Muslim women who are cognizant of the negative stereotype associated with either their ethnicity or their religion (or both) may give lower ratings for employability of those women representing the stereotyped group. In the non-Muslim mainstream context of North America, hijabis would be expected to receive lower ratings for employability; whereas, in the Muslim mainstream context of the Middle Eastern Gulf countries, non-hijabis would be expected to receive lower ratings for employability.

Although most of the literature about stereotype threat addresses the impact of negative stereotypes on performance in test-taking situations (Steele \& Aronson, 1995; Croizet \& Claire,1998; Quinn \& Spencer, 2001; Klein, Pohl, \& Ndagijimanna, 2007; Owens \& Massey, 2011), researchers have also extended the theory to apply to the context of survey responses (Davis, Silver, \& Baumer 2002), suggesting that the format and structure of a survey could parallel a formal testing environment, thus triggering stereotype threat in stigmatized groups. "The activation of stereotype threat seems to be affected by how certain tasks are framed. If a task is framed in such a way that individuals feel that their performance or responses may be judged against or evaluated in the context of a negative group stereotype, the pressure to disconfirm the negative stereotype produces anxiety that interferes with the processing of information or the ability to solve problems" (Davis, Silver, \& Baumer, 2002, p. 5). Utilizing an online survey, this research required participants to supply demographic and attitudinal information regarding their ethnicity and religion prior to evaluating a set of photos of for employability. Additionally, as the experimental conditions specifically required the participants to rate photos of women with and without hijab, the activation of stereotype threat with regard to hijab is highly plausible.

Understanding the effect of the hijab on perceptions of employability in the Middle East may be a much more complex undertaking than studying the phenomenon in Western countries. Mahfoodh (2008) points out that hijabis in Bahrain may be considered less able and less outgoing than non-hijabis; as such, women who wear hijab may be rejected from more prestigious employment opportunities due to the perceptions associated with it. On the other hand, McIntosh and Islam (2010) found that wearing the hijab opened business opportunities for female entrepreneurs in Bahrain. Emphasizing the influence of Islamic traditions on business practices in the Middle East, Hutchings, Metcalfe, and Cooper (2010) warn against generalized assumptions about equal opportunities for women due to the rapidly changing context, the wide cultural differences between countries, as well as the "equal but different" philosophy which characterizes gender relations in the region. With the political emphasis on increasing the employment opportunities of locals, especially in the UAE, research in this area has focused more on issues surrounding Arab national participation in the economy, rather than the perceptions of employability among middle and upper class expatriates, including South Asians in the region (Farrell, 2008; Hutchings, Metcalfe, \& Cooper, 2010; Mayers, Sonleitner, \& Wooldridge, 2007; Gallant, 2006; Nelson, 2004; Godwin, 2006). However, as the reliance on expatriate workers continues to exist, research on expatriate participation in UAE businesses must pay greater attention to the acceptance of expatriates into the mainstream society (Melvin, 2008; Beuthe, 2008).

\subsection{Research Question and Hypotheses}

Research Question: What is the effect of the hijab on South Asian Muslim women's perceptions of employability in the US and the UAE?

$>$ Hypothesis 1: Religious attire activates stereotype threat; in that, hijabis in the US will rate photos of hijab lower in terms of employability.

$>$ Hypothesis 2: Lack of religious attire activates stereotype threat in that non-hijabis, in the UAE will rate 
non-hijabis lower in terms of employability.

\subsection{Participants}

To limit the variability of data due to differences in ethnic background, the current study participants included South Asians of Indian, Pakistani, or Bangladeshi heritage. As South Asians have become a fabric of both US and the UAE societies through migratory circumstances (either their own or that of their family), this particular population served as an appropriate group for a cross-cultural comparison of Muslim women's perceptions of employability.

A total of 341 completed surveys were analyzed in this study. Of those, 58\% $(n=198)$ were US residents and $42 \%(n=143)$ were UAE residents. The mean age of US participants was 28.2 years with $98 \%$ of the participants between the ages of 18 and 50. Fifty percent of participants were born into a Muslim family and $44 \%$ were hijabi. The majority of US participants had earned at least a Bachelor's degree and approximately $60 \%$ were employed either full-time or part-time. The mean age of UAE participants was 26.2 years with $97 \%$ of participants between 18 and 50 years of age. Additionally, 99\% of the UAE respondents were born into a Muslim family and $57 \%$ were hijabi. In terms of educational attainment, the majority of UAE participants had earned at least a Bachelor's degree and $51 \%$ were employed either full-time or part-time.

\subsection{Measures}

In order to replicate and extend prior research regarding perceptions of hijab (Mahmud \& Swami, 2010; King \& Ahmad, 2010), full-face photographs of four Caucasian and four South Asian women were utilized to address each of the four employability conditions. Two photographs of each woman were taken, one with hijab and one without hijab. All women in the no-hijab condition had dark hair which was either very short or pulled away from her face. In order to minimize the effect of skin tone and ethnicity, the photos were rendered in grayscale with a white background (Figure 1).

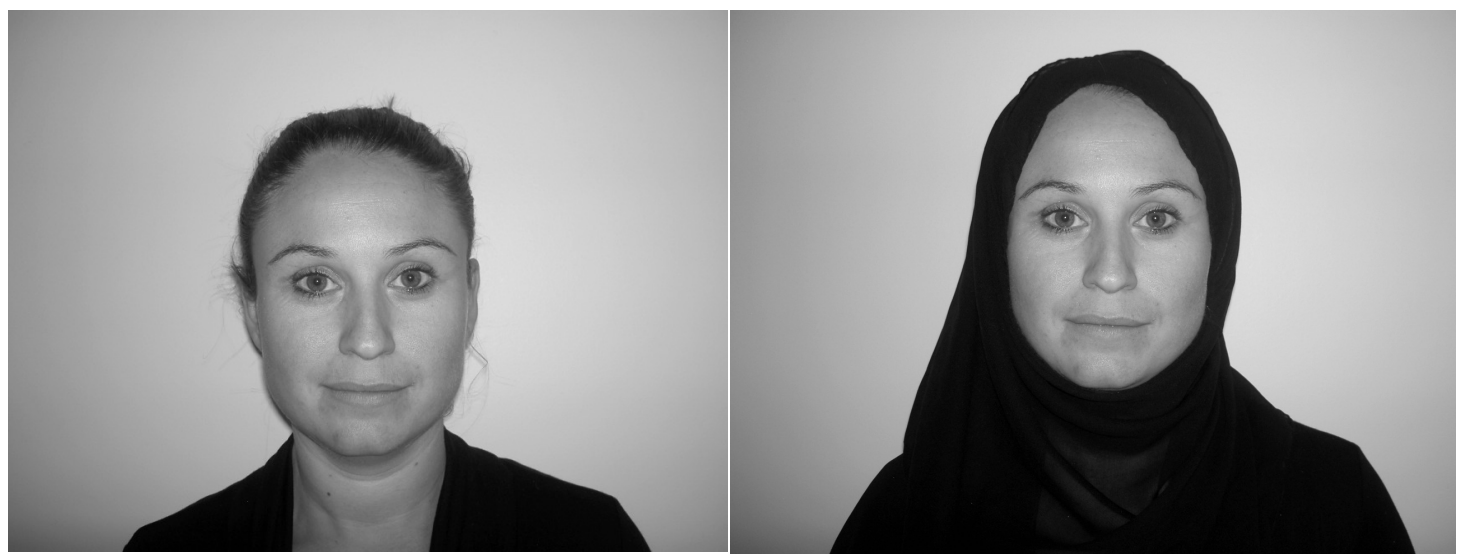

Figure 1. Experimental Condition

NOTE: Prior approval was secured in having the above pictures presented in this report.

The perceptions of employability were measured by asking participants about the likelihood of the woman in the photo obtaining a position. The survey utilized a Likert-type scale with (1) indicating "highly unlikely" to (5) indicating "highly likely". The items that measured employability were as follows:

a. This woman has applied for a job as a medical doctor. She is highly qualified for the position. In your opinion, what is the likelihood that she will obtain an offer of employment?

b. This woman has applied for a job as a laundry worker. She is highly qualified for the position. In your opinion, what is the likelihood that she will obtain an offer of employment? 
c. This woman has applied for a job as a graphic designer. She is highly qualified for the position. In your opinion, what is the likelihood that she will obtain an offer of employment?

d. This woman has applied for a job as a personal household cook for a small family. She is highly qualified for the position. In your opinion, what is the likelihood that she will obtain an offer of employment?

Content validity was established by utilizing perceived employability items based on the job types used by Ghumman and Jackson (2010) in their study of Muslim women's perceptions of employability in the United States. The internal reliability of the perceived employability items was adequate in the present study $($ Cronbach's alpha $=0.86)$.

\subsection{Procedures}

The surveys were distributed to South Asian Muslim women in the US and the UAE via the internet. While both American and Emirati mainstream societies have multicultural populations, South Asians have become part of the fabric of both societies through migration. As such, the study was limited to one cultural background while studying the perceptions of Muslim women in both a Western and an Islamic mainstream society. To present a more balanced picture of hijab, both South Asian Muslim women that wear the hijab and those that do not were asked to participate. Participants were recruited through social networking sites, university listservs, and emails to Islamic Centers in the US, as well as emails to South Asian women's associations both in the US and the UAE. These sites allowed the researcher to reach the specific demographic population that was needed for the study. Additionally organizations affiliated with Indian, Pakistani, and Bangladeshi embassies in the UAE were utilized to recruit participants living in the country.

In the request for participation letter, the researchers asked the organizations and/or individuals to pass along the survey link to other potential participants. An additional snowball sampling technique was employed; wherein, the researchers sent a recruitment email to personal acquaintances asking them to forward it to others who fit the criteria. This technique was used successfully by previous studies involving recruitment of Muslim populations (Ghumman \& Jackson, 2010; Mohammadi, Jones, \& Evans, 2008; Jana-Masri \& Priester, 2007; Peek, 2005).

Although there is no full-proof method for ensuring the identity of the participants in an online format, the recruitment emails solicited only participants from the demographic categories specified. The online survey was programmed to only allow participants to respond if they lived in either the US or the UAE. No other choice was provided on the survey and participants could not proceed until this item was completed. Participants did have the option of choosing an ethnicity other than South Asian, but the data from non-South Asians was excluded from analysis. Participants who indicated they were partly South Asian were also included in the study and final data analysis. Finally, it was imperative for participants to indicate whether they were hijabi or non-hijabi, so the survey was programmed to make this demographic item a required response that would need to be completed in order for participants to continue with the questionnaire. These efforts, both in the recruitment process and in the online administration of the survey, were made to encourage only those respondents that fit the demographic criteria to participate in the study.

To test the hypotheses associated with the research question, first the data were split by country of residence. Then, mixed 2 (hijabi x non-hijabi) x 2 (photos of hijab x photos of no-hijab) ANOVAs were conducted to test for the effect of the hijab on participants' perceptions of employability. The 2 X 2 mixed ANOVA design allowed for between subjects and within subjects analysis. The between subjects analysis compared hijabi and non-hijabi participants' responses on the two given conditions (photos of hijab and photos of no-hijab) to analyze differences between the groups regarding their perceptions of employability. Additionally, the within subjects analysis compared the responses within each group to see if there were any differences in the way that the group rated the photos of hijab versus the photos of no-hijab regarding employability . 


\section{Results}

\subsection{Hijab and employability - US}

Descriptive statistics indicated that both hijabi participants and non-hijabi participants in the US rated photos of no-hijab higher for employability than photos of hijab (Table 1).

\section{Table 1}

Descriptive Statistics for Employability Ratings by Hijab Status for US Participants

\begin{tabular}{lcccc}
\hline Employability rating & Hijabi participants & Mean & $S D$ & $N$ \\
\hline Hijab photos & Yes & 3.7 & .9 & 81 \\
& No & 3.6 & .9 & 106 \\
No-hijab photos & Yes & 4.4 & .7 & 81 \\
& No & 4.3 & .5 & 106 \\
\hline
\end{tabular}

Employability ratings of the photos of hijab and the photos of no-hijab were compared between the hijabi and non-hijabi samples as well as within each group. There was no significant interaction between participants' personal hijab status and ratings of employability, $F(1,185)=.009, p=.924$, partial $\eta^{2}=0$. However, there was a statistically significant main effect of employability ratings within the groups, $F(1,185)=119.5, p<.001$, partial $\eta^{2}=.39$, indicating a significant difference in the way that participants rated the photos of hijab versus the photos of no-hijab in terms of employability in the US. Thus, Hypothesis 1 was supported (Table 2).

Table 2

Mixed ANOVA Results for Employability Ratings by Hijab Status for US Participants

\begin{tabular}{|c|c|c|c|c|}
\hline Source & $d f$ & $F$ & $\eta^{2}$ & $p$ \\
\hline \multicolumn{5}{|c|}{ Between Subjects } \\
\hline Hijabi Status (H) & 1 & .63 & .003 & .430 \\
\hline Error & 185 & $(.761)$ & & \\
\hline \multicolumn{5}{|c|}{ Within Subjects } \\
\hline Employability (E) & 1 & $119.52 * *$ & .392 & .000 \\
\hline E X H & 1 & .009 & .000 & .924 \\
\hline Error & 185 & $(.364)$ & & \\
\hline
\end{tabular}

\subsection{Hijab and employability - UAE}

Descriptive statistics indicated that hijabi participants in the UAE rated photos of hijab higher than photos of no-hijab in terms of employability; whereas, non-hijabi participants rated photos of hijab lower in terms of employability than photos of no-hijab. Descriptive statistics for employability ratings are shown in Table 3. 
Table 3

Descriptive Statistics for Employability Ratings by Hijab Status for UAE Participants

\begin{tabular}{lcccc}
\hline Employability rating & Hijabi participants & Mean & $S D$ & \multirow{2}{*}{$N$} \\
\hline Hijab photos & Yes & 4.0 & .7 & 73 \\
& No & 3.9 & .8 & 55 \\
No-hijab photos & Yes & 3.9 & .7 & 73 \\
& No & 4.1 & .6 & 55 \\
\hline
\end{tabular}

Regarding employability ratings in the UAE, there was a significant interaction effect between participants' hijab status and their ratings of employability, $F(1,126)=5.04, p=.038$, partial $\eta^{2}=.03$, but no significant main effect of employability ratings, $F(1,126)=.59, p=.443$, partial $\eta^{2}=0$, indicating a significant difference in the way that hijabis and non-hijabis rated photos of hijab and no-hijab in terms of employability in the UAE (Table 4). Hijabi participants in the UAE rated photos of hijab higher than photos of no-hijab in terms of employability; whereas, non-hijabi participants rated photos of hijab lower in terms of employability than photos of no-hijab. Thus, Hypothesis 2 was not supported.

\section{Table 4}

Mixed ANOVA Results for Employability Ratings by Hijab Status for UAE Participants

\begin{tabular}{|c|c|c|c|c|}
\hline Source & $D f$ & $F$ & $\eta^{2}$ & $p$ \\
\hline \multicolumn{5}{|c|}{ Between Subjects } \\
\hline Hijab Status (H) & 1 & .23 & .002 & .663 \\
\hline Error & 126 & $(.761)$ & & \\
\hline \multicolumn{5}{|c|}{ Within Subjects } \\
\hline Employability (E) & 1 & .59 & .004 & .443 \\
\hline E X H & 1 & $5.04 *$ & .025 & .038 \\
\hline Error & 126 & $(.223)$ & & \\
\hline
\end{tabular}

\section{Discussion}

The present study contributes to the understanding of hijab within a Western non-Muslim mainstream context as well as a Middle Eastern Muslim one. As hypothesized, the current study found that hijabi participants in the US rated photos of hijab lower than photos of no-hijab with regard to employability. The results also showed that non-hijabis in the US rated photos of hijab lower in terms of employability than photos of no-hijab. Thus, the results of the current study support existing research (Ghumman and Jackson, 2010; Read, 2002; Persad \& Lukas, 2002; Lewis, 2007; Parker-Jenkins, Hartas, Irving, \& Barker, 1999; King \& Ahmad, 2010; Foroutan, 2008; Unkelbach, Schneider, Gode, \& Senft, 2010) and provide further evidence of the negative influence of hijab on perceptions of employability in Western societies.

As the UAE is an Islamic mainstream context, however, we hypothesized that the opposite effect would hold true, in that, non-hijabis in the UAE would rate photos of no-hijab lower than photos of hijab in terms of employability. The within groups analysis showed a difference among non-hijabis with regard to employability ratings of hijab and no-hijab photos; however, it was not in the direction that was hypothesized. Contrary to the hypothesis, non-hijabis in the UAE rated photos of hijab lower in terms of employability than photos of no-hijab. At the same time, hijabis in the UAE rated photos of hijab higher than photos of no-hijab with regard to 
employability. The limited extant literature on hijab and employability in Middle Eastern countries shows the dubious nature of the relationship where hijab can be seen as either a benefit or a detriment to employment opportunities and advancement (Mahfoodh, 2008; McIntosh \& Islam, 2010; Hutchings, Metcalfe, \& Cooper, 2010).

The perceptions of employability in this study suggest that hijabis may be perceived as less employable than non-hijabis in a Western context and to some extent in an Islamic context as well. As many Muslim women who have grown up in Western countries have high career aspirations and because there is an increasing trend toward the adoption of hijab among young Muslim women (Basit, 1996; Ali, 2005; Al-Jenaibi, 2010), this is a particularly disturbing perception. This belief may affect the self-esteem and self-efficacy of Muslim women who wear the hijab (or who are considering the option) and are interested in entering the workforce. As self-efficacy has been shown to be positively related to organizational commitment, the current study may have important implications for organizations that are looking to recruit and retain qualified personnel.

A study of 167 managers at a major engineering and transportation company in India (Sinha, Talwar, and Rajpal, 2002), for example, found a positive relationship between self-efficacy and organizational commitment. Additionally, Akhtar, Ghayas, and Adil (2012) found that self-efficacy is a predictor of organizational commitment among bank employees in Pakistan. If there is a tendency among Muslim women to feel that the hijab can act as a deterrent to employability, this may negatively affect the desire of women who wear the hijab to apply for jobs for which they may be qualified. If nothing else, this perception creates an added stressor for hijabis who are seeking employment. Thus, the results of this study verify the results of prior research that indicate the negative impact of the hijab on employability in Western contexts and extend this perception to the Islamic world.

At the same time, it is interesting to note that hijabis in the UAE perceived women wearing the hijab as more employable. As group membership affects perceptions and loyalties in that the norms of in-groups are used to judge appropriate behaviors (Klopf \& McCroskey, 2007), it is possible that in-group preferences may be more salient amongst hijabis in Islamic contexts. As a visible marker of group membership, the hijab may be used to promote the social prestige of hijabis in Islamic countries, thereby increasing members' self-esteem (Rana, 2007; Ali, 2005). Therefore, as the current study reflects, wearing the hijab in an Islamic mainstream context may promote greater perceptions of employability amongst hijabis, but not amongst non-hijabis. Furthermore, comments from participants in the present study indicated the possibility that hijab may be more or less accepted depending on the industry or the organization. As the UAE has multinational corporations as well as government industries, future research may want to explore the perceptions of hijab in different employment contexts in the Middle East.

The present study contributes to the extant literature on the impact of religious symbols in public spaces. As images of the submissive and oppressed Muslim woman continue to plague Western media outlets, it is important to provide alternate narratives of the phenomenon from within Muslim communities. The ability to obtain employment is essentially a human rights issue. The results of the present study suggest that the Islamic headscarf may limit the employability of women who choose to wear it in the public sphere. This not only has consequences for those women, but adds to the notion that Muslims are "outsiders" within Western countries. If, however, as the results suggest, hijabis are also seen as less employable within Muslim majority states, the impact of such perceptions can limit the opportunities that hijabis are given in the global job market, not just in Western contexts. However, if more hijabis can move into positions of power within global organizations, the results of the present study suggest that group cohesiveness may open doors for other qualified hijabis, at least in Muslim mainstream contexts.

\subsection{Limitations and Suggestions for Future Research}

The present exploratory study attempted to bridge the gaps in existing literature related to the influence of visible religious symbols on perceptions of employability among South Asian Muslim women in two cultural 
contexts. Interest in this area has grown as a result of 9/11 and other terrorist activities which have increased media attention on the beliefs and practices of Muslims worldwide. As the present study focused on the experience of hijab among South Asian Muslim women in the US and the UAE, there were a number of aspects of the phenomenon that were not explored.

For example, the current study did not focus on the reasons that participants chose to wear or not wear the hijab in either country. Additional research is needed in this regard to provide insight into the decision-making processes of Muslim women with respect to wearing or not wearing the hijab in Western and Islamic countries. If the hijab continues to be perceived as a hindrance to employment, it may also have implications for the application of Muslim women's educational achievements to the job market. Future research may want to follow the trends for educational levels achieved by women wearing hijab and their subsequent entry into global job markets. Future research may also want to explore generational differences as well as family influences on perceptions of hijab. As first generation South Asian immigrants tend to continue the patriarchal traditions of their home country (Das \& Kemp, 1997), the perspective of male relatives of both hijabis and non-hijabis may have some influence on the decision to wear or not wear the hijab in public spaces. As such, there may be differences in cultural values and practices between first generation and second generation Muslim women (Merz, Oort, Ozeke-Kocabas, \& Schuengel, 2009).

Future research may want to do a comparative analysis of perceptions of hijab among first generation and second generation Muslims. Differences among participants' attitudes due to their migration status as either immigrants or expatriates were also not explored. Research into the differences in attitudes of participants due to immigration status may provide additional insights into the phenomenon explored in this study.

Finally, despite the present study's attempt to narrow the cultural boundaries of the participants, some factors that may have led to variation in the experiences of these participants are age, socioeconomic status, employment status, level of education and amount of time spent in their country of residence. Future research may want to address these and other demographic factors in terms of their influence on perceptions of employability of hijabis and non-hijabis. Additionally, as the current study focused on Muslims from a South Asian (Indian, Pakistani, and Bangladeshi) background, the experience of Muslims from other cultural backgrounds was not explored; thus, it is not possible to generalize the conclusions from this study to a multicultural Muslim population. Future research may want to study the influence of hijab in other cultural contexts.

\section{Conclusion}

Although research related to Muslim practices in Western mainstream countries has increased, there is relatively little research on Muslim practices such as wearing the hijab in Islamic mainstream contexts. The current study supported previous findings regarding hijab and employability in Western contexts and added new knowledge comparing the perceptions of hijabis and non-hijabis in an Islamic context. Results of the current study reflect the need for more social and educational programs to combat stereotypes of hijab in both the Western and Islamic worlds. Stereotypes of the submissive and oppressed Muslim woman go hand in hand with images of women in traditional Islamic attire (Ruby, 2006). As a result, women who are visibly Muslim may be forced to contend with these stereotypes if they decide to follow a career path. As they continue to venture into the workforce, Muslim women who wear hijab may feel pressured to choose between employment opportunity and faith. Such a choice can create undue psychological stress which may further hinder their ability to obtain a job and in turn, confirm the negative stereotypes that already exist about women in Islam. As hijab continues to be a contentious topic with many countries imposing bans on its use in public spaces, research must continue to explore its impact on social, economic, and political domains. Research regarding hijab should also be used to initiate dialogue between Western and Islamic contexts, as well as within Muslim communities to allow diverse perspectives to be openly discussed and debated. 


\section{References:}

Ajrouch, K. J. (2007). Global contexts and the veil: Muslim integration in the United States and France. Sociology of Religion, 68(3), 321-325. http://dx.doi.org/10.1093/socrel/68.3.321

Akhter, S., Ghayas, S., \& Adil, A. (2012). Self-efficacy and optimism as predictors of organizational commitment among bank employees. International Journal of Research Studies in Psychology, 2(2), $33-42$.

Ali, S. (2005). Why here, why now? Young Muslim women wearing hijab. The Muslim World, 95, 515-530. http://dx.doi.org/10.1111/j.1478-1913.2005.00109.x

Al-Jenaibi, B. (2010). Differences between gender treatments in the workforce. Cross-Cultural Communication, $6(2), 63-74$.

Basit, T. N. (1996). 'I'd hate to be just a housewife': Career aspirations of British Muslim girls. British Journal of Guidance \& Counselling, 24(2), 227-243.

Beuthe, S. (2008). Social and cultural relations between nationals and expatriates in the Gulf Cooperation Council. (Capstone Project). University Honors International Relations.

Croizet, J. and Claire, T. (1998). Extending the concept of stereotype threat to social class: The intellectual underperformance of students from low socioeconomic backgrounds. Personality and Social Psychology Bulletin, 24, 588-594. http://dx.doi.org/10.1177/0146167298246003

Das, A. K., \& Kemp, S. F. (1997). Between two worlds: Counseling South Asian Americans. Journal of Multicultural Counseling \& Development, 25(1), 23-33. http://dx.doi.org/10.1002/j.2161-1912.1997.tb00313.x

Davis, D. W., Silver, B. D., \& Baumer, A. J. (2002). Stereotype threat and race of interviewer effects in a survey on political knowledge. State of the State Survey Briefing Paper 02-50. Institute for Public Policy and Social Research. Michigan State University.

Droogsma, R. A. (2007). Redefining hijab; American Muslim women's standpoints on veiling. Journal of Applied Communication Research, 35(3), 294-319. http://dx.doi.org/10.1080/00909880701434299

Dunn, K. M., Klocker, N., \& Salabay, T. (2007). Contemporary racism and Islamaphobia in Australia: Racializing religion. Ethnicities, 7, 564-589. http://dx.doi.org/10.1177/1468796807084017

Fair, L. S. (2003). Muslims in Denmark: Discourse of the veil. Middle States Geographer, 36, 15-24.

Foroutan, Y. (2008). Employment differentials of second generation Muslim immigrants: Assimilation and discrimination hypotheses. Immigrants \& Minorities, 26, 219-241. http://dx.doi.org/10.1080/02619280802528452

Farrell, F. (2008). Voices on Emiratization: the impact of Emirati culture on the workforce participation of national women in the UAE private banking sector. Journal of Islamic Law and Culture, 10, 107-165. http://dx.doi.org/10.1080/15288170802236374

Gallant, M. (2006). Five case studies of Emirati working women in Dubai - Their personal experiences and insights. Unpublished doctoral dissertation. University of Southern Queensland, Australia. Retrieved from http://eprints.usq.edu.au/1425/2/Gallant_2006_whole.pdf

Ghumman, S., \& Jackson, L. (2010). The downside of religious attire: The Muslim headscarf and expectations of obtaining employment. Journal of Organizational Behavior, 31, 4-23. http://dx.doi.org/10.1002/job.601

Godwin, S. M. (2006). Globalization, education and Emiratization: A study of the United Arab Emirates. The Electronic Journal on Information Systems in Developing Countries, 27, 1-14.

Gole, N. (2003). The voluntary adoption of Islamic stigma symbols. Social Research, 70, 809-828.

Heibling, M. (2008). Islamophobia in Switzerland: A new phenomenon or a new name for xenophobia? Paper prepared for Annual Conference of the Midwest Political Science Association (MPSA), Chicago, 3 - 6 April 2008

Hutchings, K., Metcalfe, B. D., and Cooper, B. K. (2010). Exploring Arab Middle Eastern women's perceptions of barriers to, and facilitators of, international management opportunities. The International Journal of Human Resource Management, 21, 61-83. http://dx.doi.org/10.1080/09585190903466863

Jana-Masri, A. and Priester, P. E. (2007). The development and validation of a Quran-based instrument to assess 
Can I get a job if I wear Hijab? Perceptions of South Asian Muslim Women in the US and the UAE

Islamic religiosity: The Religiosity of Islam Scale. Journal of Muslim Mental Health, 2, 177-188. http://dx.doi.org/10.1080/15564900701624436

Kapiszewski, A. (2006). Arab versus Asian migrant workers in the GCC countries. United Nations Expert Group Meeting on International Migration and Development in the Arab Region. United Nations Secretariat. Retrieved from www.pfcmc.com/esa/population/meetings/EGM_Ittmig_Arab/P02_Kapiszewski.pdf

King, E. B., \& Ahmad, A. S. (2010). An experimental field study of interpersonal discrimination toward Muslim job applicants. Personnel Psychology, 63, 881-906. http://dx.doi.org/10.1111/j.1744-6570.2010.01199.x

Klein, O., Pohl, S., \& Ndagijimana, C. (2007). The influence of intergroup comparisons on Africans' intelligence test performance in a job selection context. The Journal of Psychology, 141(5), 453-467. http://dx.doi.org/10.3200/JRLP.141.5.453-468

Klopf, D. W. and McCroskey, J. C. (2007). Intercultural communication encounters. Pearson: Boston.

Lewis, R. (2007). Veils and sales: Muslims and the spaces of postcolonial fashion retail. Fashion Theory, 11, 423-442. http://dx.doi.org/10.2752/175174107X250235

Mahfoodh, H. (2008). Hijab in the eyes of little Muslim women. Unpublished masteral thesis. Graduate College of Bowling Green, Ohio.

Mahmud, Y., \& Swami, V. (2010). The influence of the hijab (Islamic head-cover) on perceptions of women's attractiveness and intelligence. Body Image, 7, 90-93. http://dx.doi.org/10.1016/j.bodyim.2009.09.003

Mayers, G., Sonleitner, N., and Wooldridge, D. G. (2007). Next step: From internship to workplace participation in the United Arab Emirates. Delta Kappa Gamma Bulletin, 12-16.

McIntosh, J. C. and Islam, S. (2010). Beyond the veil: The influence of Islam on female entrepreneurship in a conservative Muslim context. International Management Review, 6, 103-109.

Melvin, K. (2008). The United Arab Emirates: Melting Pot, Mosaic, or Neither: The Case of the Indian and the Palestinian. (Capstone Project). Retrieved from http://dspace.wrlc.org/bitstream/1961/7837/1/Melvin,\%20Kendall,\%202008F.pdf

Merz, E., Oort, F. J., Ozeke-Kocabas, E., \& Schuengel, C. (2009). Intergenerational family solidarity: Value differences between immigrant groups and generations. Journal of Family Psychology, 23(3), 291-300. http://dx.doi.org/10.1037/a0015819

Mohammadi, N., Jones, T., \& Evans, D. (2008). Participant recruitment from minority religious groups: the case of the Islamic population in South Australia. International Nursing Review, 55, 393-398. http://dx.doi.org/10.1111/j.1466-7657.2008.00647.x

Moore, K. M. (2007). Visible through the veil: The regulation of Islam in American law. Sociology of Religion, 68(3), 237-251. http://dx.doi.org/10.1093/socrel/68.3.237

Nelson, C. (2004). UAE National women at work in the private sector: Conditions and constraints. Dubai: Centre for Labour Market Research \& Information (CLMRI).

Owens, J., \& Massey, D. S. (2011). Stereotype threat and college academic performance: A latent variables approach. Social Science Research, 40, 150-166. http://dx.doi.org/10.1016/j.ssresearch.2010.09.010

Parker-Jenkins, M., Hartas, D., Irving, B. A., \& Barker, V. (1999). Inclusion, exclusion and cultural awareness: Career services supporting the career aspirations of Muslim girls. Paper presented at the European Conference on Educational Research, Lahti, Finland, 22-25 September 1999.

Peek, L. (2005). Becoming Muslim: The development of a religious identity. Sociology of Religion, 66, 215-242. http://dx.doi.org/10.2307/4153097

Persad, J. V. and Lukas, S. (2002). No hijab is permitted here: A study on the experiences of Muslim women wearing hijab applying for work in the manufacturing, sales, and service sectors. Women Working with Immigrant Women. Retrieved from http://atwork.settlement.org/downloads/No_Hijab_Is_Permitted_Here.pdf

Quinn, D. M., \& Spencer, S. J. (2001). The interference of stereotype threat with women's generation of mathematical problem-solving strategies. Journal of Social Issues, 57, 55-71. http://dx.doi.org/10.1111/0022-4537.00201

Rana, A. (2007). On being a Muslim woman. Intercultural Education, 18(2), 169-175. http://dx.doi.org/10.1080/14675980701327304 
Pasha-Zaidi, N., Masson, T., \& Pennington, M. N.

Read, J. G. (2002). Challenging myths of Muslim women: The influence of Islam on Arab-American women's labor force activity. Muslim World, 92, 19-37. http://dx.doi.org/10.1111/j.1478-1913.2002.tb03730.x

Ruby, T. F. (2006). Listening to the voices of hijab. Women's Studies International Forum, 29, 54-66. http://dx.doi.org/10.1016/j.wsif.2005.10.006

Sinha, S. P., Talwar, T., \& Rajpal, R. (2002). Correlational study of organizational commitment, self-efficacy and psychological barriers to technological change, Psychologia, 45(3), 176-183. http://dx.doi.org/10.2117/psysoc.2002.176

Sheth, F. A. (2006). Unruly Muslim women and threats to liberal culture. Peace Review: A Journal of Social Justice, 18, 455-463.

Steele, C. M., \& Aronson, J. (1995). Stereotype threat and the intellectual test performance of African Americans. Journal of Personality and Social Psychology, 69, 797-811. http://dx.doi.org/10.1037/0022-3514.69.5.797

Unkelbach, C., Schneider H., Gode, K., \& Senft, M. (2010). A turban effect, too: Selection biases against women wearing Muslim headscarves. Social Psychological and Personality Science October, 4, 378-383. http://dx.doi.org/10.1177/1948550610378381

Vyas, S. (2008). Identity experiences of young Muslim American women in the post 9/11 era. Encounter, 21(2), 15-19. 